\title{
Management of Patient with Simultaneous Overt Gastrointestinal Bleeding and Myocardial Infarction with ST-Segment Elevation - Priority Endoscopy
}

This article was published in the following Dove Press journal:

Vascular Health and Risk Management

\author{
Jakub Nozewski (D) \\ Grzegorz Grzesk ${ }^{2}$ \\ Maria Klopocka ${ }^{3}$ \\ Michal Wicinski ${ }^{4}$ \\ Klara Nicpon-Nozewska ${ }^{5}$ \\ Jakub Konieczny ${ }^{6}$ \\ Adam Wlodarczyk $\mathbb{D}^{7}$ \\ 'Faculty of Health Sciences, Emergency \\ Department, Nicolaus Copernicus \\ University, Bydgoszcz, Poland; ${ }^{2}$ Faculty of \\ Health Sciences, Department of \\ Cardiology and Clinical Pharmacology, \\ Nicolaus Copernicus University, \\ Bydgoszcz, Poland; ${ }^{3}$ Faculty of Health \\ Science, Department of \\ Gastroenterology, Nicolaus Copernicus \\ University, Bydgoszcz, Poland; ${ }^{4}$ Faculty of \\ Medicine, Department of Pharmacology \\ and Therapy, Nicolaus Copernicus \\ University, Bydgoszcz, Poland; ${ }^{5}$ Faculty of \\ Health Sciences, Department and Clinic \\ of Geriatrics, Nicolaus Copernicus \\ University, Bydgoszcz, Poland; ${ }^{6}$ Clinic of \\ Emergency, Biziel's Hospital, Bydgoszcz, \\ Poland; ${ }^{7}$ Faculty of Medicine, Department \\ of Psychiatry, Medical University of \\ Gdansk, Gdansk, Poland
}

Correspondence: Jakub Nozewsk Department of Emergency Medicine, Faculty of Health Science, Nicolaus Copernicus University in Toruń, Collegium Medicum, Jagiellońska 13-15, Bydgoszcz, 85-067, Poland

Tel +48 667109009

Email jbnoz@wp.pl
Background: The current ERC guidelines are the source of many positive changes, reduction of mortality, length of hospitalization and improvement of prognosis of STEMI patients. However, there is a small group of patients whose slight modification in guidelines would further reduce in-hospital mortality and hospitalization costs. These are patients with concomitant STEMI infarction and gastrointestinal bleeding.

Methods: Two separate methods of treatment were compared in patients with concomitant gastrointestinal bleeding and ST-segment elevation myocardial infarction. The first - traditional approach, in the line with the ESC guidelines, the second innovative, with priority for endoscopy.

Results: Despite the innovative approach, the patient with endoscopy before PCI was discharged without complication. A patient who has undergone coronary intervention and who has been started on typical antiplatelet therapy prior to gastroenterological diagnosis has died due to massive bleeding.

Conclusion: For ethical reasons and in connection with the cardiological guidelines of the management of ACS, a study of patients with ASC a high risk of intestinal bleeding, in which endoscopy will have priority, and only later PCI, will probably never be performed. Although, as the described case shows, despite exceeding the 90 minutes time to implement PCI $(<120$ minutes $)$ in logistic terms such behavior is completely feasible.

Keywords: upper gastrointestinal bleeding, acute coronary syndrome, antiplatelet and anticoagulant therapy, hemorrhage shock, proton pump inhibitors, endoscopy

\section{Summary}

We currently have guidelines for the management of acute coronary syndromes. There are also distinct guidelines for gastrointestinal bleeding. These guidelines are supported by many studies, often on several hundred thousand patients, comparison of different groups of drugs, procedures depending on the time since the onset of symptoms, dose of drugs depending on concomitant diseases and procedures, scale of risk of recurrence of symptoms and long-term recommendations - often to end of life. Unfortunately, there are no recommendations for the management of patients who report to hospital with symptoms of acute coronary syndrome and overt bleeding from the gastrointestinal tract - at the same time (before antiplatelet therapy). Below we present a review of the scientific literature and a comparison 
of two methods supported by cases of patients with symptoms of gastrointestinal bleeding and acute coronary syndrome.

\section{Background}

\section{Management of Gastrointestinal Bleeding}

Upper gastrointestinal bleeding (UGIB) is a life-threatening condition associated with bleeding proximal to the Trietz ligament. It occurs with a frequency of 100 cases/100,000 inhabitants/year. Compared to bleeding from the lower gastrointestinal tract, it occurs $4 \mathrm{x}$ more often, and also has a much higher mortality rate of 6-10\%, depending on the source and $2 \mathrm{x}$ more often in men. ${ }^{1-9}$ The most common cause of upper gastrointestinal bleeding is gastric ulcer $(27-40 \%$ of all bleeding episodes). ${ }^{10}$ Risk factors for upper gastrointestinal bleeding are alcohol abuse, renal failure, H. pylori infection and non-steroidal anti-inflammatory drugs (NSAID) use. ${ }^{11}$ By blocking cyclooxygenase, NSAID cause a reduced secretion of prostaglandins - a factor that protects the mucosa from the harmful effects of low $\mathrm{pH}$. Up to $70 \%$ of NSAID users develop endoscopic lesions, mainly in antrum. ${ }^{12}$ Immediate intake increases the risk of developing a gastric ulcer by 40 times and increases the risk of developing a duodenal ulcer by 8 times. ${ }^{13}$ The most common symptoms of upper gastrointestinal bleeding include coffee ground vomiting, tarry or bloody stools, fainting, collapsing, epigastric pain, dyspepsia, sternum burning. Management of a patient depends on the patient's condition, shock symptoms, hemoglobin level on admission, comorbidities, causes of bleeding and prognosis. The guidelines from the International Consensus Group do not recommend the use of the AIMS65 scale or the Glasgow-Blatchford score or the pre-endoscopic Rockall scale in Emergency Departments to identify patients with low risk of re-bleeding and a low probability of dying from bleeding as patients who can be safely prescribed for outpatient treatment. It was determined that none of the scales in an acceptable percentage can predict the risk of recurrence of bleeding and that no scale can be substituted for the overall clinical assessment by experienced personnel. During patients stay in the Emergency Department, in the case of non-varicose UBIG, it is recommended to give a bolus of $80 \mathrm{mg}$ proton pump inhibitor (PPI) intravenously, followed by a continuous infusion of $8 \mathrm{mg} / \mathrm{h}$ for 48-72 h. Such actions are aimed at increasing the $\mathrm{pH}$ in the stomach $>6.0$, and thus there is a greater likelihood of protecting the clot formed from ulceration against fibrinolysis. ${ }^{14}$ Incorporation of PPI into treatment prevents recurrence of bleeding, the need for repeat endoscopy or surgical intervention. ${ }^{15-17}$ In the presence of hemodynamic instability symptoms, emergency "CAB" management (circulation, airways, breathing) is very important. For patients with symptoms of hemorrhagic shock, fluid resuscitation should be used as soon as possible. At the moment we do not have any data showing the predominance of colloids over crystalloids or the use of permissive hypotension instead of aggressive fluid therapy. ${ }^{18-26}$ For massive bleeding, the 3-for-1 rule applies. Each $\mathrm{mL}$ of lost blood is supplemented with $3 \mathrm{~mL}$ of crystalloids, bearing in mind concomitant cardiovascular diseases. In the case of anemia, transfusion of red blood cells or whole blood is recommended to reach a hemoglobin $(\mathrm{Hg})$ level of 8.0 $\mathrm{g} / \mathrm{dl}$, and for patients with cardiovascular disease $>8.0 \mathrm{~g} / \mathrm{dl}$. Numerous studies have proven the advantage of such restrictive behavior over achieving higher $\mathrm{Hg}$ values. $^{27-32}$ It is recommended to insert an intragastric probe for each patient. There is no scientific data that could suggest a risk of damage, and hence increased bleeding in a patient with esophageal varices. $^{33}$ In the presence of fresh blood or coffee ground content, there is a $93 \%$ certainty of upper gastrointestinal bleeding. ${ }^{34}$ However, in $15.9 \%$ of the patients with clear suction aspirated contents, massive duodenal ulceration bleeding was found in endoscopy. ${ }^{35}$ Based on the vast majority of studies, endoscopy is recommended within $24 \mathrm{~h}$ of admission, as this reduces the length of hospitalization and the cost of treatment in patients with low risk of recurrence. In patients with high risk of recurrence of bleeding, endoscopy within 24 $\mathrm{h}$ reduces 30 -day mortality. In the meta-analysis of 20 cohort studies based on data from hospitals in which 24-h endoscopic duty was not performed, it was proved that patients admitted with symptoms of upper gastrointestinal bleeding during oncall hours are less likely to have endoscopic treatment within $24 \mathrm{~h}$, therefore higher risk of death. ${ }^{36}$ Endoscopy is not recommended before compensating hemodynamic instability. In $72.3 \%$ of the patients, the co-morbidity is given as the main cause of death in gastrointestinal bleeding, not bleeding alone. $^{37-39}$ Hence, in patients taking antithrombotic drugs before gastrointestinal bleeding signs occur, several studies recommend continuing antithrombotic therapy after an episode of upper gastrointestinal bleeding to prevent the development of serious thrombotic complication. However, careful assessment of the risk and possible benefits of continuing or re-entering antithrombotic therapy can sometimes be very demanding. Aspirin is the best studied drug influencing blood clot, in this respect. The decision to continue aspirin therapy after a bleeding episode depends on whether it was used for primary or secondary prevention prior to bleeding. The benefits of continuing secondary prevention are $27 \mathrm{x}$ 
greater than those primary. ${ }^{40}$ One hundred and fifty-six patients with gastric bleeding who were taking aspirin for secondary prevention were divided into two groups: those who continued therapy and those who were discontinued due to the bleeding episode. Mortality within 8 weeks of bleeding episode in the continuing treatment group was $1.3 \%$, in the group where treatment was discontinued $-12.9 \%{ }^{41}$ In primary prevention, the benefits of continuing treatment do not outweigh the risk of bleeding, but after the bleeding source has healed, depends on indications or clinical situation, treatment may be restarted.

\section{Management of Acute Coronary Syndrome}

Acute myocardial infarction is defined on the basis of clinical, electrocardiographic, biochemical and pathological characteristics. Acute coronary syndrome includes three different clinical manifestations of ischemic disease: unstable angina, ST-segment elevation myocardial infarction (NSTEMI) and ST-segment elevation myocardial infarction. Diagnosis is usually based on the presence of characteristic symptoms: nonreactive to nitroglycerin, retrosternal chest pain lasting at least 10-20 min (also possible localization is epigastric or interscapular pain). Pain often radiates to the left shoulder, neck, lower jaw and right shoulder. It has a squeezing, tearing, sometimes burning character. A history of coronary artery disease or acute coronary syndrome risk factors, often with a positive family history are present. Pain is accompanied by various symptoms resulting from stimulation of the autonomic system secondary to fear of death and severe pain, eg, pallor, sweating, low pulse pressure, nausea. In the period immediately preceding the onset of pain, fatigue, shortness of breath, fainting or fainting, and indigestion-like symptoms occur. An electrocardiographic examination should be performed as soon as possible, based on which we distinguish two groups of patients: those with ST-segment elevation (STEMI), which usually indicates complete coronary artery occlusion, and those without ST-segment elevation or transient ST-segment elevation. The definition of myocardial infarction means necrosis of cardiomyocytes in a clinical situation corresponding to acute myocardial ischemia. A combination of several criteria is required to diagnose acute myocardial infarction, ie, detection of an increase and/or decrease in cardiac biomarkers, preferably cardiac troponins marked with high-sensitivity tests, with at least one value $>$ the 99th percentile of the upper reference limit and at least one of the following:
1. Signs of ischemia

2. New or presumably new diagnostic ST-T lesions or left bundle branch block in a 12-lead ECG

3. The appearance of pathological Q waves on the ECG

4. Confirmed in imaging tests a newly created or presumably new loss of viable myocardium or segmental wall movement disorders

5. Determination of intravascular thrombus in angiography or post-mortem examination

Based on data from 2018, there are 156 cardiological centers in Poland undertaking interventional ACS treatment. There were 738 STEMI attacks, 1256 NSTEMI attacks and 979 cases of unstable angina (UA) per million inhabitants. Inhospital mortality for STEMI is $10.5 \%$ and NSTEMI $7.3 \%$. The main cause of death was cardiogenic shock, as well as delayed treatment due to atypical ASC symptoms in women. A year after STEMI, $18 \%$ of patients die. Still nearly $1 / 3$ of patients with symptoms of myocardial infarction do not go directly to the hospital with the Cath Lab undertaking cardiological interventions, but to the center without such a workshop which unnecessarily and sometimes also significantly increases the time to implement the procedure.

There are 5 types of myocardial infarction:

1) Type 1 myocardial infarction: when the cause of myocardial necrosis is the mechanical closure of one or more coronary vessels

2) Type 2 myocardial infarction: when the cause of myocardial necrosis, beyond the atherosclerotic plaque is a disturbed balance between delivery and demand for coronary oxygen

3) Death of a patient with angina symptoms, recent ECG changes before obtaining a troponin (TNI) result

4) Myocardial infarction associated with percutaneous coronary intervention (PCI), stent thrombosis or restenosis

5) Myocardial infarction associated with coronary artery bypass grafting (CABG)

Physical examination of people with ACS (apart from the symptoms of stimulation of the sympathetic nervous system mentioned above) often does not show any abnormalities. In almost $1 / 3$ of patients, the ECG performed during the first 10 min does not show any abnormalities. Patients with ST-segment depression $>0.5 \mathrm{mV}$ in 2 or more adjacent leads in ECG have a worse prognosis. In unstable patients, start with emergency "CAB" management (circulation, airways, breathing) and implement 
symptomatic treatment. In stable patients, typical management involves the supply of:

- oxygen - in the case of saturation $<90 \%$,

- nitrates - intravenous administration is more effective than sublingual ones. Contraindicated in hypotension and infarction with ST-segment elevation from the inferior wall (leads II, III, aVF) as well as in patients who took sildenafil within $24 \mathrm{~h}$ or vardenafil within $48 \mathrm{~h}$,

- beta blockers - are used routinely, except for patients at high risk of cardiogenic shock $(>70$ years of age, with heart rate $(\mathrm{HR})>110 / \mathrm{min}$, with systolic blood pressure (SBP) $<120 \mathrm{mmHg}$ ) since the supply B-blockers in this group within 24 admission increase the risk of shock or death. It should be remembered that B-blockers are also contraindicated in patients whose symptoms result from coronary artery spasm or cocaine use.

- MF - analgesic treatment is aimed at providing the greatest comfort to the patient, as well as preventing too much activation of the sympathetic nervous system, and thus vasoconstriction and increasing the afterload. We give morphine intravenously at an initial dose of 4-8 $\mathrm{mg}$ and depending on the patient's response, another $2 \mathrm{mg}$ intravenously every 5-15 min. It should be remembered that morphine inhibits the intestinal passage and may interfere with the absorption of orally administered antiplatelet agents, as well as anti-aggregation drugs.

\section{Dual Antiplatelet Therapy}

The standard of care for patients with ACS is dual antiplatelet therapy (DAPT). It includes acetylsalicylic acid (ASA) and one of the P2Y receptor inhibitors. DAPT aims to reduce the activation of platelets and inhibit their aggregation at the site of damage to the endothelium (in which the atherosclerotic plaque has developed) or on the surface of exogenous materials. Regardless of the strategy, DAPT is recommended immediately after diagnosis. Two-year ASA administration (since ACS diagnosis) is associated with a $46 \%$ reduction in the risk of a vascular incident. In the CURRENT-OASIS 7 study, patients undergoing PCI did not show differences between the $75 \mathrm{mg}$ and $325 \mathrm{mg}$ ASA dose; however, the guidelines recommend a dose of 150-300 mg p.o. (per os) (uncoated tablets) or $150 \mathrm{mg}$ intravenously. Contraindications to the use of ASA are allergy to acetylsalicylic acid, active gastrointestinal bleeding, coagulation disorders or cirrhosis. Oral inhibitors of $\mathrm{P} 2 \mathrm{Y}$ platelet purinergic receptor for adenosine 5-diphosphate (ADP) are recommended by European Society of Cardiology for 12 months after ASC, regardless of strategy. Ticagrelor at a loading dose of $180 \mathrm{mg}$ p.o. is indicated immediately after diagnosis, followed by $90 \mathrm{mg}$ 2 times a day as the first choice drug from the group of P2Y inhibitors. If a patient receives clopidogrel, it should be discontinued and ticagrelor should be included. In the absence of ticagrelor, clopidogrel should be given. Ticagrelor is the active form of the drug, it works within 30 min of oral administration, its binding to the P2Y12 receptor is reversible, hence after discontinuation of the drug platelet activity begins to return after several hours. Ticagrelor is metabolized by CYP3A4, which is why on its pharmacokinetics impact have several commonly used drugs. The effect of ticagrelor prolongs among others ketoconazole and clarithromycin; the opposite effect is observed with the simultaneous use of dexamethasone, carbamazepine, phenobarbital and rifampicin. It has been proven (PLATO study The Phase III PLATelet inhibition and patient Outcomes) that ticagrelor reduces risk of death without increasing risk of bleeding when compared to clopidogrel. Clopidogrel is a thienopyridine derivative, a prodrug, in order for its anti-aggregation potential to be revealed, it must undergo its two-stage (oxidation and subsequent hydrolysis) conversion in the liver with the help of cytochrome P450. At a loading dose of $600 \mathrm{mg}$ followed by $75 \mathrm{mg}$ daily p.o. Due to the necessity of metabolism to the active substance, its activity is revealed after 2-4 h, however, unlike ticagrelor, it blocks the P2Y receptor irreversibly, therefore its activity lasts throughout the life of platelets, ie, about $120 \mathrm{~h}$. Peak inhibition of platelet aggregation after administration of clopidogrel occurs after about $6 \mathrm{~h}$. The oxidation of clopidogrel to 2-oxo-clopidogrel occurs mainly with the help of CYP2C19, CYP3A4 and CYP2B56 cytochrome P-450 isoenzymes. The normal function of the cytochrome is associated with the CYP2C19* 1 allele. Due to the presence of CYP isoenzyme genes in the general population, the so-called "poor metabolizers" include persons with the allele of converting function loss - CYP2C19*2 and CYP2C19*3. Depending on the tests carried out for platelet activity, $5-44 \%$ of the people taking clopidogrel have a lower than predicted degree of inhibition of platelet activity. The CYP2C19 * 2 mutation occurs in nearly $30 \%$ of the Caucasian population, which is associated with an up to 6-fold higher risk of death from thrombotic causes. Higher platelet aggregation activity after clopidogrel is also found in the elderly, obese, smokers, with diabetes and/or renal failure. There were no elevated platelet aggregation values after administration of ticagrelor in subjects 
with cytochrome P450 isoenzymes disturbance (RESPOND study). Another drug from the P2Y receptor inhibitors group is prasugrel. The new generation thienopyridine, like clopidogrel, is a prodrug, but only one-step conversion is needed to reveal its antiplatelet activity, making it work faster. Similar to clopidogrel, it irreversibly inhibits ADP-induced activation of the GPIIb/IIIa complex. Prasugrel is used at a loading dose of $60 \mathrm{mg}$, then $10 \mathrm{mg}$ once a day. Prasugrel can be used with other drugs metabolized by cytochrome P-450 enzymes, and the restriction of the enzyme $\mathrm{CP} 2 \mathrm{C} 19$ in conversion to the active metabolite means that resistance to its effects is much less frequent compared to clopidogrel. Prasugrel is contraindicated in patients with a history of stroke or transient ischemic attack (TIA). In addition, the benefits of prasugrel have not been demonstrated in patients with body weight $<60 \mathrm{~kg}$ or over 75 years of age. The other groups of drugs are heparins, GP IIb/IIIa antagonists, bivalirudin, fondaparinux and fibrinolytics.

\section{Methodology}

\section{First Case}

A 64-year-old man was brought to the Emergency Department by an ambulance team after fainting in a sitting position preceded by chest pain. Blood pressure - 70/50 $\mathrm{mmHg}$ measurement taken by ambulance staff, heart rate $110 / \mathrm{min}$, saturation $96 \%$ while he was breathing ambient air. In Emergency
Department patient was stable: BP 150/94 mmHg, HR 98/min. He reported permanent non-radiation sternal stinging, for last few days has been giving away post-workout feeling of tightness in the chest, disappearing at rest. He was smoking cigarettes for 20 years approx. a packet a day. Recently he has not noticed any other disturbing ailments. In ECG - regular sinus rhythm, 100/min, intermediate axis, Q wave in III, aVF, lowering the ST segment in I, aVL, V4-V6. In the physical examination, sweaty skin of normal color, auscultatory symmetrical follicular murmur. The abdomen was soft without tenderness, audible peristalsis, no aneurysm type changes. No limb edema visible. Admission test results were presented in Table 1. Last available hemoglobin test result (3 months before) was $14.5 \mathrm{~g} / \mathrm{dl}$. In connection with reported hypotension, 5000 heparin units were administered to the patient, secondary to pulmonary embolism suspicion, $2 \mathrm{mg}$ morphine was given because of pain. Angio-CT of the thoracic vessels was performed and no embolic material was found. The patient was transferred to the Cardiology Department with suspected acute coronary syndrome.

In the Department of Cardiology, troponin TNI 0.045 was checked. Echocardiographic examination was performed, which showed: enlargement of the left atrium size (in $4 \mathrm{Ch} 4.1 \times 4.8 \mathrm{~cm}$ ), significant left ventricular hypertrophy (IVS in the middle part at $4 \mathrm{Ch}$ to $1.8 \mathrm{~cm}$ ), marked hypokinesis of the basal segments of the inferior wall and ventricular septum, hyperkinesis of the remaining segments

Table I Blood Test Results of Patient I During His Hospitalization

\begin{tabular}{|c|c|c|c|c|c|}
\hline & $\begin{array}{l}\text { I Day } \\
\text { | 3:00 }\end{array}$ & $\begin{array}{l}\text { I Day } \\
20: 00\end{array}$ & $\begin{array}{l}\text { II Day } \\
\text { I 4:00 }\end{array}$ & $\begin{array}{l}\text { II Day } \\
\text { 19:00 }\end{array}$ & Norm \\
\hline WBC & 15.52 & II.87 & 12.07 & 26.62 & $3.9-10.2 \mathrm{G} / \mathrm{l}$ \\
\hline RBC & 3.94 & 3.32 & 2.2 & 1.44 & $4.5-5.5$ \\
\hline HGB & 12.9 & 10.9 & 7.3 & 4.6 & $14-18$ \\
\hline HCT & 37.7 & 31.3 & 20.5 & 14.4 & $40-54$ \\
\hline $\mathrm{MCV}$ & 95.7 & 94.3 & 93.2 & 100.0 & $80-99$ \\
\hline $\mathrm{MCH}$ & 32.7 & 32.8 & 33.2 & 31.9 & $27-33.5$ \\
\hline $\mathrm{MCHC}$ & 34.2 & 34.8 & 35.6 & 31.9 & 31.37 \\
\hline RDW & 12.4 & 12.2 & 12.4 & 16.2 & $11.5-14.5$ \\
\hline PLT & 287 & 262 & 208 & 55 & $130-400 \mathrm{G} / \mathrm{I}$ \\
\hline $\mathrm{Na}+$ & 137 & & & & $135-145 \mathrm{mmol} /$ \\
\hline $\mathrm{K}+$ & 4.34 & & & & $3.5-0.0 \mathrm{mmol} / \mathrm{l}$ \\
\hline Creat. & 0.96 & & & & $0.67-1.17 \mathrm{mg} / \mathrm{dl}$ \\
\hline GFR & 83 & & & & $>90 \mathrm{~mL} / \mathrm{min}$ \\
\hline CRP & 12.6 & & & & $<5 \mathrm{mg} / \mathrm{dl}$ \\
\hline Troponin & 0.026 & 0.045 & & & $<0.014 \mathrm{ng} / \mathrm{mL}$ \\
\hline $\mathrm{T}$ hs & & & & & \\
\hline D-dimers & 4209 & & & & $<500 \mathrm{ng} / \mathrm{mL}$ \\
\hline
\end{tabular}


of the left ventricle with an estimated ejection fraction (EF) of $60 \%$. The patient was transported to the Cath Lab, where coronary angiography was performed: in right coronary artery (RCA) on the border of the 2nd and 3rd segment $80 \%$ narrowed, first right posterolateral (RPL) closed in $100 \%$ shows collateral circulation from left coronary artery (LCA), left anterior descending (LAD) critically narrowed in $95 \%$. Pressure was symmetrical on both arms - 70/50 mmHg with HR 130/min during the procedure. Fifty micrograms of fentanyl and $1000 \mathrm{~mL}$ of $\mathrm{NaCl} 0.9 \%$ were administered and transferred to the intensive cardiac supervision room for observation. Approximately 2 hours after coronary angiography, the patient gave a brown stool with a lot of fresh blood, a gastric tube was inserted without obtaining pathological content, morphology was checked and a surgical consultation was requested. The consulting surgeon recommended crossing the blood and ordering 2 blood units, discontinuing antiplatelet drugs, qualified the patient for endoscopy within $24 \mathrm{~h}$. Control morphology results are presented in Table 1. During the night shift, the patient was stable, no tarry stool or blood/coffee ground vomiting were observed again. Approx. at 12 o'clock on the second day of hospitalization, the patient began to vomit with a large amount of fresh blood. Endoscopic team and surgeons were called urgently. Eighty milligrams of PPI i.v. and $8 \mathrm{~mL} / \mathrm{h}$ PPI infusion were given immediately. Two units of fresh frozen plasma (FFP) and 2 units of packed red blood cell (pRBC) were given, test results from critical parameters analyzer - hemoglobin $10.1 \mathrm{~g} / \mathrm{dl}$ were made prior to administration of blood preparations. Due to the large amount of blood, hypotension and difficulty in visualizing the source of bleeding in the endoscopy, the patient was urgently taken to the operating theater. In the operating theater, after opening the coatings, the following were seen: pale internal organs, small intestines translucent hemolyzed blood content, after performing gastrotomy, a large amount of liquid blood content and fresh clotted blood were found in the stomach, the source of bleeding was found in the prepyloric region from the side of the smaller curvature in the form of large ulceration in diameter $15 \mathrm{~mm}$ with protruding actively bleeding artery. Hemostasis was obtained by puncturing the vessel (Safil 0). During the procedure, cardiac arrest occurred and cardio-pulmonary resuscitation (CPR) was carried out for several dozen minutes to restore spontaneous blood circulation. The patient was transferred to the Intensive Care Unit on the infusion of Levonor and Adrenaline in an extremely severe condition. Due to deep acidosis and the appearance of DIC (disseminated intravascular coagulation), the patient died after $10 \mathrm{~h}$ in the ICU despite intensive treatment.

\section{Second Case}

A 52-year-old patient reported to the Hospital Emergency Department at 08:09 because of recurrent chest tightness for a few hours, pain was not related to body position and respiratory phase, he also reported that he gave a tarry stool just before reporting to the hospital. In history: hypertension (HA), ankylosing spondylitis, stage IV renal failure, nephrolithiasis. The last available hemoglobin result 5 months ago $13.1 \mathrm{~g} / \mathrm{dl}$ (Table 2). In recent days, he reported the severity of back pain, which leads to taking ketoprofen $200 \mathrm{mg} /$ day. On examination: full logical contact, HR 90/min, BP 120/80 $\mathrm{mmHg}$, over the lung fields - symmetrical follicular murmur, abdominal arched above the level of the chest, soft, painless, with normal peristalsis, peritoneal symptoms absent, swelling of the lower limbs around the ankles, symmetrical. In rectal examination - tarry stool. ECG: regular sinus rhythm, frequency 90/min. Intermediate axis. RBBB. ST-segment elevation in I, II, aVL, V2-V6. In connection with the diagnosis of ST-segment elevation myocardial infarction and simultaneous gastrointestinal bleeding, a decision was made to transfer the patient to an Endoscopic Laboratory as a matter of urgency, assisted by a specialist in emergency medicine and resuscitation team, the Hemodynamics Laboratory was informed about the arrival of patients with STEMI within $60 \mathrm{~min}, 80 \mathrm{mg}$ PPI was given i.v. and $8 \mathrm{mg} / \mathrm{h}$ PPI continuous infusion has started, O Rh- universal blood

Table 2 Blood Test Result of Patient 2 During Hospitalization

\begin{tabular}{|l|l|l|l|}
\hline & I Day (09:00) & III Day & Norm \\
\hline WBC & 10.33 & 8.68 & $3.9-10.2 \mathrm{G} / \mathrm{I}$ \\
RBC & 2.89 & 2.07 & $4.5-5.5$ \\
HGB & 9.1 & 6.2 & $14-18$ \\
HCT & 26.9 & 18.6 & $40-54$ \\
MCV & 93.1 & 89.9 & $80-99$ \\
MCH & 31.5 & 30.0 & $27-33.5$ \\
MCHC & 33.8 & 33.3 & 31.37 \\
RDW & 13.4 & 17.6 & $11.5-14.5$ \\
PLT & 272 & 193 & $130-400 \mathrm{G} / 1$ \\
Na+ & 137 & 143 & $135-145 \mathrm{mmol} / /$ \\
K+ & 4.04 & 4.19 & $3.5-0.0 \mathrm{mmol} / /$ \\
Creat. & 2.33 & 3.02 & $0.67-1.17 \mathrm{mg} / \mathrm{dl}$ \\
GFR & 31 & 23 & $>90 \mathrm{~mL} / \mathrm{min}$ \\
CRP & 11.2 & 28.2 & $<5 \mathrm{mg} / \mathrm{dl}$ \\
Troponin T hs & 0.104 & 2.07 & $<0.014 \mathrm{ng} / \mathrm{mL}$ \\
Ca2+ & 1.97 & & \\
\hline
\end{tabular}


was ordered and the patient's blood group crossed. At 9:15 gastroscopy was performed, which showed: esophagus unchanged, stomach prone to insufflation; dusty content at the bottom, groove in inversion unchanged, gastric mucosa beyond pallor without pronounced changes, shaped bulb, quite deep in its lower part, about $8-10 \mathrm{~mm}$ ulcer, with a fresh, non-flushable thrombus, without signs of active bleeding, due to the planned anti-clotting treatment, two hemostatic clips were successfully placed. The patient in very good general condition was forwarded at 9:50 to the Cath Lab, where $85 \%$ stenosis was found in LAD, 1 drugreleasing stent (DES) was put on, the full dose was administered: ticagrelor $180 \mathrm{mg}$ p.o., ASA $300 \mathrm{mg}$ p.o., heparin $5000 \mathrm{j}$ i.v. and from the next day recommended $75 \mathrm{mg}$ ASA daily and ticagrelor $90 \mathrm{mg}$ p.o.

\section{Discussion}

\section{Professor M. Klopocka (Head of Gastroenterology Clinic)}

We perform annually in our Clinic about 200 urgent interventions and about 5500 scheduled gastroscopies and colonoscopies, we run 24-h endoscopic shifts. At present, there are no clear guidelines for the management of patients with concomitant gastrointestinal bleeding and ACS at admission to hospital. It is estimated that $5 \%$ of the patients will experience gastrointestinal bleeding after acute coronary syndrome, and based on the ACUITY study, we know that gastrointestinal bleeding coexists in $1.1-3.5 \%{ }^{42-44}$ of the patients with ACS. We have few scientific works on how to deal with patients who are directly after PCI and who have gastrointestinal bleeding during one stay. We know that this complication extends the duration of hospitalization (9.79 days to 21.84 days), increases the cost of treatment, and above all increases hospital mortality from $7.2 \%$ to $21.3 \%$. The above cases describe two different procedures for patients with ACS symptoms and upper gastrointestinal bleeding (unfortunately the first patient did not show any overt bleeding during admission). Interestingly, the first patient did not have any risk factors for upper gastrointestinal bleeding (they are listed in Table 3A - based on the CRUSADE scale), however, at the first contact with the ambulance team and in the hemodynamics laboratory, he presented symptoms suggesting bleeding (Table 3B) that did not subside despite PTCA, which due to the lack of overt bleeding symptoms was underestimated. In the case of
Table 3 Risk Factors for Upper Gastrointestinal Bleeding in Patients with ACS

A. Risk factors for upper gastrointestinal bleeding in patients with
acute coronary syndrome
- Age $>70$ years old
- Female
- Diabetes
- Heart failure
- Renal failure
- Nicotine addiction
- Use of nonsteroidal anti-inflammatory drugs (NSAIDs)
- History of gastrointestinal bleeding
B. Symptoms, vital signs and test results in patients with ASC
indicating a highly probable co-occurrence or occurrence of upper
gastrointestinal bleeding
- HR $>100 /$ min
- BP < $60 \mathrm{mmHg}$
- Anaemia
- PLT < $100.000 / \mathrm{mm}^{3}$
- PT < $70 \mathrm{~s}$
- eGFR $<60 \mathrm{~mL} / \mathrm{ph} / \mathrm{l} .73 \mathrm{~m}^{2}$
- Left Ventricular Ejection Fraction $<40 \%$
- The need for pressure amines
- Pneumonia

gastrointestinal bleeding, the main cause of mortality is not bleeding itself, but comorbidities - in this case, acute coronary syndrome. It is difficult to refuse a patient with ACS symptoms and gastrointestinal bleeding a typical cardiac treatment. Based on the above cases, symptomatic treatment of gastrointestinal bleeding consisting of the administration of proton pump inhibitors does not always give the expected results, and often such a treatment is not started at all. Based on a retrospective study of $>800$ patients with acute coronary syndrome, $46.3 \%$ of the patients were at high risk of bleeding ( $>10$ points on the REPLACE scale), but PPI treatment was only started in half of them. ${ }^{45}$ Endoscopy in uncomplicated acute coronary syndrome is not contraindicated ${ }^{46,47}$ but the risk of a serious incident associated with it is much higher than in the case of the planned procedure $1 \%$ vs $0.0004 \%$. Based on the research in a group of 874 patients with ACS, 9 patients required esophagogastroduodenoscopy within 5 days after PCI, one person had cardiac arrest during the procedure despite normal hemodynamic parameters and $\mathrm{Hg} 11.0 \mathrm{~g} / \mathrm{dl}{ }^{48}$ However, the best time to perform endoscopy in patient with ACS and high bleeding risk remains inexplicable. 


\section{How Gastroenterologist Sees Caring for Such a Patients}

A patient with symptoms of upper gastrointestinal bleeding with a recent onset and co-occurring ASC should have an endoscopy before PCI. Medical history, drug used, precise examination, including rectal examination or gastric lavage after probe placement are not able to rule out bleeding with certainty. Nearly $15 \%$ of the patients with normal gastric lavage have bleeding from a duodenal ulcer. Bleeding at a recent onset will not cause tarry stools (like in patient 1); morphology often remains normal during the first hours of bleeding. Administration of DAPT and heparin in a patient with active upper gastrointestinal bleeding will intensify bleeding, as a result of progressive inadequate blood supply may lead to type 2 infarction, and if necessary surgery it will significantly increase hemorrhagic complications. DAPT significantly reduces ACS-related mortality, but we are well aware that in both ACS and gastrointestinal bleeding, a whole series of platelet-activating pro-thrombotic mediators are released, not only through P2Y: thrombin via PAR 1 receptor, catecholamines via alpha and beta receptors, TXA2 through the Tp-alpha receptor, collagen through the glycoprotein VI (GPVI), prostacyclin via the IP receptor, hence DAPT alone does not provide $100 \%$ certainty that clot will not occur. The magnitude of bleeding complications after DAPT is directly proportional to mortality in patients with ASC. Treatment in case of bleeding involves the administration of a proton pump inhibitor, we have data that PPI has an advantage over H2blokers in the case of UGIB as a complication of treatment with aspirin, clopidogrel, enoxaparin or fibrinolysis after ACS. If in endoscopy the source of bleeding was localized and endoscopic treatment was effective, or if there were no signs of active bleeding, I would have included DAPT. If the bleeding source was not visible, bleeding symptoms persist, I would recommend treatment with blood products, PPI for $72 \mathrm{~h}$ and the inclusion of a short-acting ADP antagonist ticagrelor without ASA; possibly cangrelor (not yet available in Poland) for $24 \mathrm{~h}$, and after that time perform another endoscopy and green light assessment for DAPT. In case of lack of endoscopy, in patients with bleeding symptoms, in stable patients, I would propose PCI with clot aspiration, direct endoscopy after the procedure in another hospital.

\section{Professor G. Grzesk (Head of Cardiology Clinic)}

We perform 2000 PCI annually in the Cardiology Clinic, we hospitalize patients with symptoms of stable and unstable angina. Acute coronary syndrome to which gastrointestinal bleeding is applied simultaneously is a challenge for interventional cardiologists. The presented cases show two completely different ways of proceeding, including one endoscopy before PCI - risky innovative. The guidelines make it clear that a patient with ACS, should have PCI performed within 90 min from first contact with healthcare and primary PCI without fibrinolytic treatment should be preferred in these cases. Multicenter studies have proven the numerous benefits of such a management. The guidelines, however, do not look for a way to manage ACS with overlapping gastrointestinal bleeding. As clinicians, we often encounter gastrointestinal bleeding a few days after starting standard treatment, but active fresh gastrointestinal bleeding before PCI is casuistic. Aspirin in such patients certainly increased bleeding but has a proven mortality-reducing effect, a lower dose should be considered because the risk of bleeding is directly proportional to the dose used (CURE study). In a study conducted several years ago, bleeding was found in $20 \%$ of the patients treated with PCI who were treated with ASA and heparin or vitamin $\mathrm{K}$ antagonist (VKA) compared to $0 \%$ in patients who received only ASA after PCI. The groups consisted of 138 and 109 people, respectively. The average bleeding time was 2.5 days, a large group were patients without any bleeding risk factors, $25 \%$ of those at risk of bleeding in endoscopy had a gastric ulcer. Several research suggests that patients with high risk of bleeding should have a bare metal stent (BMS) which has more benefits than drug-eluting stent (DES) in those patients (NORSTENT study). In these patients, you can also consider using a balloon without using a stent. Although studies of new polymeric DES show more benefits in patients with high bleeding risk (compared to BMS) in 390-day follow-up and using DAPT for only 30 days!

As a clinical pharmacologist, I can add that bivalirudin as inhibitor of thrombin-induced conversion of fibrinogen to fibrin can by helpful in this case. Research was also presented on a group of patients undergoing PCI with a bivalirudin infusion, based on which it has been proven that bivalirudin reduces the risk of bleeding and mortality compared to traditional therapy (heparin UHF + GP IIb/IIIa inhibitor), however, compared to the group of patients with STEMI in whom heparin alone was used; the results obtained for bleeding risk were almost identical. Bivalirudin should be continued for up to $3 \mathrm{~h}$ after PCI. During that time endoscopy may be considered, using $8 \mathrm{mg} / \mathrm{h}$ infusion of PPI since the suspected bleeding is extended. As for heparin, enoxaparin is preferred, rather than low molecular weight heparin (UFH), but bleeding more often occurs during the treatment of first 
mentioned. ${ }^{49}$ Considering the above and having an antidote for heparin, the use of heparin should be considered - in the case of bleeding or uncontrollable bleeding, use protamine sulfate, which inactivates heparin by forming stable, inactive complexes with it. One milligram of intravenous protamine sulfate inactivates $100 \mathrm{IU}$ heparin. It should be remembered that protamine sulfate used in too high dose alone has antiaggregation effect. Unfortunately, there are no studies on the use of protamine sulfate in patients with ACS. In the case of absolute necessity to discontinue DAPT, ESC guidelines do not offer other equally effective therapy. When implementing a patient with symptoms of gastrointestinal bleeding, typical anti-aggregation therapy should take into account the littleknown paradoxical effects of blood products often used in bleeding to maintain $\mathrm{Hg}>8$.0. It has been proven that the use of red blood cell products in patients with recent NSTEMI increases the risk of re-ACS by $25 \%$ and the risk of death by $8 \%$. The cause of higher mortality in patients with NSTEMI after $\mathrm{RBC}$ use is unknown. It is recommended to use leukocyte-poor pRBC stored less than 2 weeks.

\section{Summary}

The two ways of proceeding presented are completely different. Each of the specialists try to convince the priority of their treatment. However, imagine such discussion in the Emergency Department where we are limited by the time and availability of drugs mentioned in the discussion. As emergency department employees, we consider the procedure in which endoscopy is performed before PCI as more logical and subsequent cases should confirm the legitimacy of such a management.

\section{Conclusions}

Due to the lack of transparent guidelines for management with patient with ACS and UGIB, management will depend only on the decision of ambulance staff and Emergency Department crew to whom the patient will be brought. In accordance with the guidelines, patients with retrosternal pain and ischemic changes with ECG will receive a full dose of drugs from the ambulance team and will be transported directly to Cath Lab. Endoscopic treatment will be implemented probably after the development of full-blown hemorrhagic shock. When ambulance personnel demonstrate vigilance and awareness of the risk of coexistence of UGIB and ACS and the patient referred to Emergency Department after gastroenterology consultation have opportunity for endoscopic treatment and then antiplatelet therapy and PCI. For ethical reasons, incidentally nature and in connection with high-level evidence of cardiology guidelines, a research in which patients with ASC and co-existent upper gastrointestinal bleeding will have endoscopy first, and only later PCI, will probably never be performed. The scheme for this can be considered in patients with NSTEMI and high risk of bleeding. Although, as the case described shows, despite exceeding the 90-min time to implement PCI $(<120 \mathrm{~min})$ in terms of logistics, such behavior is completely feasible. Following guidelines regardless of clinical case can sometimes lead to dire consequences.

\section{Abbreviations}

ACS, acute coronary syndrome; ADP, adenosine 5-diphosphate; ASA, acetylsalicylic acid; BMS, bare metal stent; CABG, coronary artery bypass grafting; DAPT, Dual antiplatelet therapy; DES, drug-eluting stent; ECG, electrocardiogram; EF, ejection fraction; FFP, fresh frozen plasma; $\mathrm{Hg}$, hemoglobin; HR, heart rate; LAD, left anterior descending coronary artery; LCA, left coronary artery; NSAID, non-steroidal anti-inflammatory drug; PCI, percutaneous coronary intervention; PPI, proton pump inhibitor; pRBC, packed red blood cell; RPL, right posterolateral coronary artery; SBP, systolic blood pressure; TNI, troponin I; UGIB, upper gastrointestinal bleeding.

\section{Data Sharing Statement}

The datasets during and/or analysed during the current study available from the corresponding author on reasonable request.

\section{Consent for Publication}

Present.

\section{Author Contributions}

All authors contributed to data analysis, drafting or revising the article, have agreed on the journal to which the article will be submitted, gave final approval of the version to be published, and agree to be accountable for all aspects of the work.

\section{Funding}

There is no funding to report.

\section{Disclosure}

The authors declare that they have no conflicts of interest.

\section{References}

1. Al-Assi MT, Genta RM, Karttunen TJ, Graham DY. Ulcer site and complications: relation to Helicobacter pylori infection and NSAID use. Endoscopy. 1996;28(2):229-233. doi:10.1055/s-2007-1005433 
2. Frattaroli FM, Casciani E, Spoletini D, et al. Prospective study comparing multi-detector row CT and endoscopy in acute gastrointestinal bleeding. World J Surg. 2009;33(10):2209-2217. doi:10.1007/s00268-009-0156-6

3. Lam KL, Wong JC, Lau JY. Pharmacological treatment in upper gastrointestinal bleeding. Curr Treat Options Gastroenterol. 2015;13(4):369-376. doi:10.1007/s11938-015-0063-x

4. Curdia-Goncalves T, Rosa B, Cotter J. New insights on an old medical emergency: non-portal hypertension related upper gastrointestinal bleeding. Rev Esp Enferm Dig. 2016;108(10):648-656.

5. Lirio RA. Management of upper gastrointestinal bleeding in children: variceal and nonvariceal. Gastrointest Endosc Clin N Am. 2016;26 (1):63-73.

6. Fallah MA, Prakash C, Edmundowicz S. Acute gastrointestinal bleeding. Med Clin North Am. 2000;84(5):1183-1208. doi:10.1016/ S0025-7125(05)70282-0

7. Pongprasobchai S, Nimitvilai S, Chasawat J, Manatsathit S. Upper gastrointestinal bleeding etiology score for predicting variceal and non-variceal bleeding. World J Gastroenterol. 2009;15 (9):1099-1104. doi:10.3748/wjg.15.1099

8. Straube S, Tramer MR, Moore RA, Derry S, McQuay HJ. Mortality with upper gastrointestinal bleeding and perforation: effects of time and NSAID use. BMC Gastroenterol. 2009;9:41. doi:10.1186/1471230X-9-41

9. Yavorski RT, Wong RK, Maydonovitch C, Battin LS, Furnia A, Amundson DE. Analysis of 3294 cases of upper gastrointestinal bleeding in military medical facilities. Am J Gastroenterol. 1995;90 (4):568-573.

10. Stabile BE, Stamos MJ. Surgical management of gastrointestinal bleeding. Gastroenterol Clin North Am. 2000;29(1):189-222. doi:10.1016/S0889-8553(05)70112-6

11. Cheung FK, Lau JY. Management of massive peptic ulcer bleeding. Gastroenterol Clin North Am. 2009;38(2):231-243. doi:10.1016/j. gtc.2009.03.003

12. Larkai EN, Smith JL, Lidsky MD, Graham DY. Gastroduodenal mucosa and dyspeptic symptoms in arthritic patients during chronic nonsteroidal anti-inflammatory drug use. Am J Gastroenterol. 1987;82(11):1153-1158.

13. Corson JD, Williamson RCN, eds. Surgery. London, UK: MosbyYear Book; 2001.

14. Lau JY, Leung WK, Wu JC, et al. Omeprazole before endoscopy in patients with gastrointestinal bleeding. $N$ Engl J Med. 2007;356 (16):1631-1640. doi:10.1056/NEJMoa065703

15. Laine L, Shah A, Bemanian S. Intragastric $\mathrm{pH}$ with oral vs intravenous bolus plus infusion proton-pump inhibitor therapy in patients with bleeding ulcers. Gastroenterology. 2008;134(7):1836-1841. doi:10.1053/j.gastro.2008.03.006

16. Leontiadis GI, Sharma VK, Howden CW. Proton pump inhibitor therapy for peptic ulcer bleeding: cochrane collaboration meta-analysis of randomized controlled trials. Mayo Clin Proc. 2007;82(3):286-296. doi:10.1016/S0025-6196(11)61024-0

17. Leontiadis GI, Sharma VK, Howden CW. Systematic review and meta-analysis of proton pump inhibitor therapy in peptic ulcer bleeding. BMJ. 2005;330(7491):568. doi:10.1136/ bmj.38356.641134.8F

18. Perel P, Roberts I, Ker K. Colloids versus crystalloids for fluid resuscitation in critically ill patients. Cochrane Database Syst Rev. 2013. doi:10.1002/14651858.CD000567.pub6

19. Cha' vez-Negrete A, Majluf CS, FratiMunari A, et al. Treatment of hemorrhagic shock with intraosseous or intravenous infusion of hypertonic saline dextran solution. Eur Surg Res. 1991;23:123-129. doi:10.1159/000129144

20. Annane D, Siami S, Jaber S, et al. CRISTAL Investigators. Effects of fluid resuscitation with colloids vs crystalloids on mortality in critically ill patients presenting with hypovolemic shock: the CRISTAL randomized trial. JAMA. 2013;310:1809-1817. doi:10.1001/ jama.2013.280502
21. Semler MW, Self WH, Wanderer JP, et al. Balanced crystalloids versus saline in critically ill adults. $N$ Engl J Med. 2018;378:829-839. doi:10.1056/NEJMoa1711584

22. Kowalenko T, Stern S, Dronen S, et al. Improved outcome with hypotensive resuscitation of uncontrolled hemorrhagic shock in a swine model. J Trauma. 1992;33:349. doi:10.1097/00005373199209000-00003

23. Stern SA, Dronen SC, Birrer P, et al. Effect of blood pressure on hemorrhage volume and survival in a near-fatal hemorrhage model incorporating a vascular injury. Ann Emerg Med. 1993;22:155-163. doi:10.1016/S0196-0644(05)80195-7

24. Kwan I, Bunn F, Chinnock P, et al. Timing and volume of fluid administration for patients with bleeding. Cochrane Database Syst Rev. 2014. doi:10.1002/14651858.CD002245.pub2

25. Schreiber MA, Meier EN, Tisherman SA, et al. A controlled resuscitation strategy is feasible and safe in hypotensive trauma patients: results of a prospective randomized pilot trial. J Trauma Acute Care Surg. 2015;78:687. doi:10.1097/TA.0000000000000600

26. Carrick MM, Morrison CA, Tapia NM, et al. Intraoperative hypotensive resuscitation for patients undergoing laparotomy or thoracotomy for trauma: early termination of a randomized prospective clinical trial. J Trauma Acute Care Surg. 2016;80:886-896. doi:10.1097/ TA.0000000000001044

27. Carson JL, Guyatt G, Heddle NM, et al. Clinical practice guidelines from the AABB: red blood cell transfusion thresholds and storage. JAMA. 2016;316:2025-2035. doi:10.1001/jama.2016.9185

28. Docherty AB, O'Donnell R, Brunskill S, et al. Effect of restrictive versus liberal transfusion strategies on outcomes in patients with cardiovascular disease in a non-cardiac surgery setting: systematic review and meta-analysis. BMJ. 2016;352:i1351. doi:10.1136/bmj.i1351

29. Blair SD, Janvrin SB, McCollum CN, Greenhalgh RM. Effect of early blood transfusion on gastrointestinal haemorrhage. $\mathrm{Br} J$ Surg. 1986;73:783-785. doi:10.1002/bjs.1800731007

30. Villanueva C, Colomo A, Bosch A, et al. Transfusion strategies for acute upper gastrointestinal bleeding. N Engl J Med. 2013;368:11-21. doi:10.1056/NEJMoa1211801

31. Jairath V, Kahan BC, Gray A, et al. Restrictive versus liberal blood transfusion for acute upper gastrointestinal bleeding (TRIGGER): a pragmatic, open-label, cluster randomised feasibility trial. Lancet. 2015;386:137-144. doi:10.1016/S0140-6736(14)61999-1

32. Odutayo A, Desborough MJ, Trivella M, et al. Restrictive versus liberal blood transfusion for gastrointestinal bleeding: a systematic review and meta-analysis of randomised controlled trials. Lancet Gastroenterol Hepatol. 2017;2:354-360. doi:10.1016/S24681253(17)30054-7

33. Monteiro S, Goncalves TC, Magalhaes J, Cotter J. Upper gastrointestinal bleeding risk scores: who, when and why? World J Gastrointest Pathophysiol. 2016;7(1):86-96.

34. Green FW, Kaplan MM, Curtis LE, Levine PH. Effect of acid and pepsin on blood coagulation and platelet aggregation. A possible contribut or prolonged gastroduodenal mucosal hemorrhage. Gastroenterology. 1978;74(1):38-43. doi:10.1016/0016-5085(78) 90352-9

35. Adler DG, Leighton JA, Davila RE, et al. ASGE guideline: the role of endoscopy in acute non-variceal upper-GI hemorrhage. Gastrointest Endosc. 2004;60(4):497-504. doi:10.1016/S00165107(04)01568-8

36. Xia XF, Chiu PWY, Tsoi KKF, et al. The effect of off-hours hospital admission on mortality and clinical outcomes for patients with upper gastrointestinal hemorrhage: a systematic review and meta-analysis of 20 cohorts. United Eur Gastroenterol J. 2018;6:367-381. doi:10.1177/2050640617732651

37. Sung JJ, Tsoi KK, Ma TK, Yung MY, Lau JY, Chiu PW. Causes of mortality in patients with peptic ulcer bleeding: a prospective cohort study of 10,428 cases. Am J Gastroenterol. 2010;105:84-89. doi:10.1038/ajg.2009.507 
38. Barkun AN, Bardou M, Kuipers EJ, et al. International consensus recommendations on the management of patients with nonvariceal upper gastrointestinal bleeding. Ann Intern Med. 2010;152:101-113. doi:10.7326/0003-4819-152-2-201001190-00009

39. Chassaignon C, Letoumelin P, Pateron D, Group HD. Upper gastrointestinal haemorrhage in emergency Departments in France: causes and management. Eur J Emerg Med off J Eur Soc Emerg Med. 2003;10:290-295. doi:10.1097/00063110-200312000-00010

40. Laine L, Solomon CG. Upper gastrointestinal bleeding due to a peptic ulcer. $N$ Engl J Med. 2016;374:2367-2376. doi:10.1056/ NEJMcp1514257

41. Sung JJ, Lau JY, Ching JY, et al. Continuation of low-dose aspirin therapy in peptic ulcer bleeding: a randomized trial. Ann Intern Med. 2010;152:1-9. doi:10.7326/0003-4819-152-1-201001050-00179

42. Ergelen M, Uyarel H, Soylu O, et al. Gastrointestinal bleeding in patients undergoing primary angioplasty for acute myocardial infarction: incidence, risk factors and prognosis. Turk Kardiyoloji Dernegi Arsivi. 2010;38:101-106.

43. Tanigawa T, Watanabe T, Nadatani Y, et al. Gastrointestinal bleeding after percutaneous coronary intervention. Digestion. 2011;83:153-160. doi:10.1159/000321813

44. Chua SK, Liao C-S, Hung H-F, et al. Gastrointestinal bleeding and outcomes after percutaneous coronary intervention for ST segment elevation myocardial infarction. Am J Crit Care. 2011;20:218-225. doi:10.4037/ajec2011683
45. Badar A, Scaife J, Yan AT, et al. Provision of gastroprotective medication and bleeding risk following acute coronary syndrome. J Invasive Cardiol. 2013;25:397-401.

46. Mumatz K, Ismail FW, Jafri W, et al. Safety and utility of oesophago-gastro-duodenoscopy in acute myocardial infarction. Eur J Gastroenterol Hepatol. 2008;20(1):51-55. doi:10.1097/ MEG.0b013e3282f16a3a

47. Lin S, Konstance R, Jollis J, Fisher DA. The utility of upper endoscopy in patients with concomitant upper gastrointestinal bleeding and acute myocardial infarction. Dig Dis Sci. 2006;51 (12):2377-2383. doi:10.1007/s10620-006-9326-7

48. Vavlukis M. Incidence of major gastrointestinal bleeding in patients with acute coronary syndrome treated with dual antiplatelet and anticoagulant therapy-data from the registry. EC Gastroenterol Digestive Syst. 2017;2:398-410.

49. Steg PG, James SK, Atar D, et al.; Task Force on the management of ST-segment elevation acute myocardial infarction of the European Society of Cardiology (ESC). ESC guidelines for the management of acute myocardial infarction in patients presenting with ST-segment elevation. Eur Heart J. 2012;33(20):2569-2619. doi:10.1093/eurheartj/ehs 215 .
Vascular Health and Risk Management

\section{Publish your work in this journal}

Vascular Health and Risk Management is an international, peerreviewed journal of therapeutics and risk management, focusing on concise rapid reporting of clinical studies on the processes involved in the maintenance of vascular health; the monitoring, prevention and treatment of vascular disease and its sequelae; and the involvement
Dovepress

of metabolic disorders, particularly diabetes. This journal is indexed on PubMed Central and MedLine. The manuscript management system is completely online and includes a very quick and fair peerreview system, which is all easy to use. Visit http://www.dovepress. com/testimonials.php to read real quotes from published authors. 